\title{
Auditory verbal hallucinations in first-episode psychosis: a phenomenological investigation
}

Rachel Upthegrove, Jonathan Ives, Matthew R. Broome, Kimberly Caldwell, Stephen J. Wood and Femi Oyebode

\section{Background}

In dimensional understanding of psychosis, auditory verbal hallucinations $(\mathrm{AVH})$ are unitary phenomena present on a continuum from non-clinical voice hearing to severe mental illness. There is mixed evidence for this approach and a relative absence of research into subjective experience of AVH in early psychosis.

\section{Aims \\ To conduct primary research into the nature of subjective experience of $\mathrm{AVH}$ in first-episode psychosis.}

\section{Method}

A phenomenological study using diary and photo-elicitation qualitative techniques investigating the subjective experience of AVH in 25 young people with first-episode psychosis.

\section{Results}

$\mathrm{AVH}$ are characterised by: (a) entity, as though from a living being with complex social interchange; and (b) control, exerting authority with ability to influence. AVH are also received with passivity, often accompanied by sensation in other modalities.

\section{Conclusions}

A modern detailed phenomenological investigation, without presupposition, gives results that echo known descriptive psychopathology. However, novel findings also emerge that may be features of $\mathrm{AVH}$ in psychosis not currently captured with standardised measures.

\section{Declaration of interest}

None.

\section{Copyright and usage}

(c) The Royal College of Psychiatrists 2016. This is an open access article distributed under the terms of the Creative Commons Non-Commercial, No Derivatives (CC BY-NC-ND) licence.
Hallucinations are considered a fundamental symptom within psychiatry. ${ }^{1}$ Auditory verbal hallucinations (AVH) in psychosis were richly explored by Jaspers, Bleuler and Kraepelinin in the early 20 th century ${ }^{2}$ and from this legacy focus has continued on AVH as a sensory perception in the auditory modality, principally in the form of speech, in the absence of external stimuli. ${ }^{2,3}$ However, it is increasingly recognised that $\mathrm{AVH}$ can occur in otherwise healthy individuals with rates of up to $20 \%$ of the population ${ }^{4}$ and can also occur in a range of non-psychotic illnesses, including posttraumatic stress disorder and borderline personality disorder. ${ }^{5}$ To what extent AVH in non-clinical and non-psychotic populations is the same phenomena as AVH as a symptom of psychosis is unclear. One recent qualitative study of AVH in a mixed clinical and non-clinical sample, reporting experiences online, showed no clear distinctions between these two groups. ${ }^{6}$ Slotema et al similarly found no clear distinctions of AVH described by patients with schizophrenia as opposed to patients with borderline personality disorder. ${ }^{7}$ In neurobiological investigations, there is more evidence of a distinction; Looijestijn $\mathrm{et}_{\mathrm{al}}^{8}$ investigated sound localisation and demonstrated that only in psychosis were external AVH related to increased activity in the left planum temporale and right middle frontal gyrus cluster. Howes et $a l,{ }^{9}$ in a positron emission tomography study, showed altered dopamine synthesis capacity only underlies hallucinations occurring in patients with psychosis One difficulty may be that current studies often use standardised measures of $\mathrm{AVH}$ or questionnaires with yes/no responses, and these do not capture the rich features that may distinguish subtypes of AVH or unique features in psychosis. Stanghellini et al emphasise this possibility, having investigated the distinction between psychotic and non-psychotic AVH over and above that gained by standard AVH measures. Participants were encouraged to provide further detailed descriptions, and those provided by patients with schizophrenia were very different to that provided by the nonpsychotic group. ${ }^{10} \mathrm{AVH}$, as currently defined, may also be a poor way to distinguish a prodrome of a psychotic disorder. The occurrence of attenuated or infrequent $\mathrm{AVH}$ has been used, in part, to define the risk of developing a psychotic illness. 'Transition' to psychosis is made at a point predefined by standard criteria heavily influenced by the frequency of AVH, yet the clinical significance of this transition and role of AVH therein is challenged. ${ }^{11}$

Thus, as currently defined, AVH may show poor specificity for psychosis, and we suggest that an increase in primary phenomenological data is needed. The term 'phenomenology' has been used to label the detailed description of clinical features, signs and symptoms observed in pathological conditions, as well as being a method of analysing subjective experience that is rooted in a particular philosophical tradition. A phenomenological approach in this latter sense begins with the premise that the analysis of direct description can provide significant understanding and insight into the nature of the experience itself. Here, phenomenology is defined by a commitment to lay bare the 'essence' of any experience, independent of its causation. ${ }^{12}$ In the context of a research methodology, phenomenology is characterised by a systematic investigation of subjectivity and a consideration of experience from the firstperson perspective and can be viewed as the foundational science for psychopathology. ${ }^{13}$ The need to get at a true subjective experience may be particularly challenging in the experience of voice hearing in severe mental illness, whereby other positive symptoms such as persecutory delusions and cognitive and negative symptoms may form barriers to the communication of detailed accounts. Various methods have been used in the past to gain improved access to rich subjective data in psychosis in studies that focus on help-seeking, recovery and the meaning of experience. ${ }^{14-16}$ When using a phenomenological approach to understand actual symptoms, 
we have previously used photo-elicitation ethnography in postpsychotic depression, finding this methodology helpful in increasing participants' ability to communicate their experiences. ${ }^{17}$

In this study, we aim for a modern description of AVH in psychosis based on a 'naive' exploration of the 'concrete life worlds' of those who experience this symptom. We aim to understand AVH phenomenology using an approach that does not attempt to relate an individual's experience to known or existing diagnostic or explanatory factors, and thus acknowledge the possibility of an entirely new framework emerging.

\section{Method}

A qualitative cross-sectional study using phenomenological and ethnographic methods was conducted with participants experiencing $\mathrm{AVH}$ as part of first-episode psychosis. We selected early psychosis as this would allow access to participants with clinically significant AVH at a time prior to repeated interactions with healthcare staff, whose interview questions and communication may frame an individual's understanding of their own experience.

Participants were recruited from the Birmingham Early Intervention Service, which covers areas of a diverse range of socioeconomic and ethnic communities. ${ }^{18}$

Participants were included if they had the capacity to consent and were currently experiencing AVH at least every other day; this was to ensure that voice hearing was present currently and participants were not relying on memory of past experiences. The only exclusion criterion was an inability to communicate adequately in English. All patients meeting inclusion criteria, within 1 year of treatment onset, were invited to participate regardless of diagnostic category within psychosis. A pro forma was used to gather baseline demographic data of age, gender, occupational status and ethnicity. Diagnosis was as defined by consultant psychiatrist after clinical interview using ICD-10 RCD criteria. ${ }^{19}$ National Health Service ethical approval was obtained and included the anonymous publication of direct quotes (NRES 13/WM/0277).

\section{Phenomenological interviews}

An in-depth interview was conducted with each participant. We used three approaches aimed at facilitating communication of individual experience; diary, photo-elicitation ethnography and an open walking interview. Diary entries and photos were used to stimulate discussion during interviews, where questions were flexible and unstructured, based on topics the participant wishes to discuss.

\section{Diary and photo elicitation}

One week prior to the interview, each participant was provided with a diary and asked to write down their experiences of AVH (i.e. what the event is like and how it makes them feel). We gave participants broad instructions about what to record.

Concurrently with the diaries, participants received a disposable camera and were asked to take photos of anything they believe represents aspects of their experiences of AVH. The photoelicitation approach has proven to be a valuable method of obtaining a deeper understanding of people, their outlook on the world and, thus, their own lives. ${ }^{20}$ Photos and their subsequent significance reveal meanings which are generally not accessed in a typical interview situation. ${ }^{21}$ Photo elicitation allows for higher levels of reflective thinking, as well as adding credibility to the data. ${ }^{17,22}$

Diaries and cameras were collected 7 days after being given to participants, and 2-3 days before the qualitative interview. Films were developed and photos printed, so that participants and interviewer could handle the photos during the walking interview. We discussed thoroughly the use of a visual medium (photos) to aid conveyance of the experience of auditory phenomena; we concluded that the 'heard' nature of AVH was a presupposition and that the use of photos may allow a different understanding to emerge.

\section{Walking interview}

Rather than adopting a room-based style of interview, which may replicate negative power dynamics within healthcare or lead to a closed down 'question and answer' interaction, participants were asked to describe their experiences in an open environment. The mobile interview is considered a useful method of enabling participants to express their thoughts more clearly, since discussion takes place side to side (i.e. and not face to face), putting participants at ease. ${ }^{17}$ In a project that seeks to open up the possibility for new understandings, it is important to ensure that participants are not in a frame of mind where they simply replicate what they have been told about their condition in clinical encounters. Having an interview experience that was an unlike a clinical interview as much as possible was therefore seen as advantageous.

Opening questions included: 'Could you tell me a bit about this particular (diary) entry' and 'Could you explain how this particular photograph relates to your experience?' Thus, interviews were based on each individual's communication of the nature of their own experiences and bespoke to each participant.

All dialogue was digitally recorded and transcribed verbatim. Recruitment continued until data saturation, that is, no codes or themes emerging (refer to Analysis and Results sections).

\section{Analysis}

Data were analysed using conventional content analysis. ${ }^{23}$ The stepwise analytic process involved: (a) immersion in the data and making sense of it as a whole. Transcripts were read several times before units of analysis (codes) were selected; and (b) data organisation through a process of coding, followed by categorisation to describe the phenomena were generated, and grouped into sub/ higher-order categories. ${ }^{24}$ Care was taken to ensure that the findings were both credible and trustworthy, with various 'triangulation' checks performed on the analysis as it emerged. Initial analysis was conducted by K.C., who had regular meetings with R.U. and J.I. to discuss and develop the emerging codes and categories. Further, less regular meetings were held between K.C., R.U., J.I., S.J.W., M.R.B. and F.O. to discuss the emerging analysis and consider alternative perspectives.

\section{Results}

Twenty-five participants with first-episode psychosis met inclusion criteria and consented to participate in the study. At this point of recruitment, data saturation was reached. See Table 1 for demographic and clinical description of the sample. In this paper, we report findings related to the quality of AVH experience. Two overarching themes captured participants' descriptions of the quality of their voices: entity and control. Within each theme are codes and subcodes.

\section{Entity}

Codes within this theme reflect AVH experienced as though the voice belongs to an entity. We use the term entity here to encompass all those features that speak to the reality and veridical nature of their experience, rather than participants reporting a visitation or other additional experience of entity. However, as demonstrated by the number of codes within this theme, a label of 'reality' was felt to be insufficient on its own. AVH were experienced as speaking with all the features of character, interaction and individuality of a living being (Fig. 1 and Table 2). 


\begin{tabular}{|lc|}
\hline Table 1 Clinical and demographic details \\
\hline Characteristic \\
\hline Age, years (range) & $26(17-37)$ \\
\hline Male, \% & 69 \\
\hline Ethnicity, $n$ (\%) & $14(56)$ \\
White & $7(28)$ \\
Asian & $4(16)$ \\
Black & $1(4)$ \\
\hline Occupational status, $n$ (\%) & $18(72)$ \\
Employed & $1(4)$ \\
Unemployed & $3(12)$ \\
Away from work & $2(4)$ \\
Student & $11(44)$ \\
Other & $2(8)$ \\
\hline Diagnosis, $n$ (\%) & $12(48)$ \\
\hline Schizophrenia & \\
Schizoaffective & 279 \\
Psychosis not otherwise specified & 209 \\
\hline Duration of untreated psychosis, days \\
Mean
\end{tabular}

\section{Clarity and volume}

Overall, the audible quality of voices was described as being both clear and loud, but volume could vary with voice intent and content.

\section{Veridicality}

Real. Participants frequently spoke about the absolute concrete presence of their voices, typically comparing this to the likeness of having or overhearing an actual conversation. As a result, many found it difficult to distinguish between reality and what they were currently experiencing. Participants talked about surprise in realising that others could not hear their voices.

Familiarity. There was a perceived familiarity of voices reported. Voices spoke using voices from participants' significant family members or from other individuals within their personal history in an intimate and personal communication.

\section{Multiple}

It was common (11 out of 25 participants) to hear multiple voices; these could be a combination of male and female, adults and children, taking turns to speak or talking simultaneously. Several participants reported that their voices could speak different languages, with one individual referring to these as his 'community'. Those who frequently experienced multiple voices often described these in terms of the voices' personal characteristics, good or bad, nasty, etc.
Locus

Voices are experienced as either internal (i.e. coming from inside participants' heads) or external (i.e. coming from elsewhere) occurrences. Although the location of voices was clearly a factor raised by participants, this was a varied experience that changed with time and situation. The location of voices did not appear to affect their auditory quality or the 'realness' of the experience. Participants reported identifying where voices were coming from could be difficult to establish.

\section{Control}

Many codes were related to a passive experience of AVH; this was experienced as more than a commanding voice, although this did occur. Control not only reflects voice authority but also the ability to exert physical and emotional influence and be disruptive to day-to-day life. It also reflects the participants' perception of voice impositions and being a passive recipient of an imposed experience, often occurring in more than one sensory modality.

\section{Authority}

In general, voices were experienced as being authoritative and powerful, demonstrating an ability to succeed in attempts to control the experience. Participants frequently referred to their voices as 'strong' and, in contrast, described themselves as being too 'weak' to stop them. Some reported that their voices took complete charge over thoughts and lives. One participant spoke about her struggle to control her voice, describing how she often felt overpowered by its 'pull'. The power of voices was also associated with their unpredictability.

\section{Ability to control behaviour}

Participants often reported feeling their behaviour was influenced by their voices. This was experienced in many forms.

Demanding. Voices were frequently described as being demanding, giving specific instructions to be followed. In total, 13 of 25 (52\%) participants reported a demanding voice. This included commands which would often be given in a manner that prevented opportunity for further thought or discussion from the participants. We have chosen the label 'demand' rather than 'command' as although the content is an instruction, the term command infers a power with the order being given with the expectation it will be followed. This was not always present in participant's direct reports. A demanding voice implies a struggle between the request given, albeit firmly asked, and the authority with which it is given. A smaller number, 9 of 25 (32\%) participants, reported a demanding voice with authority.

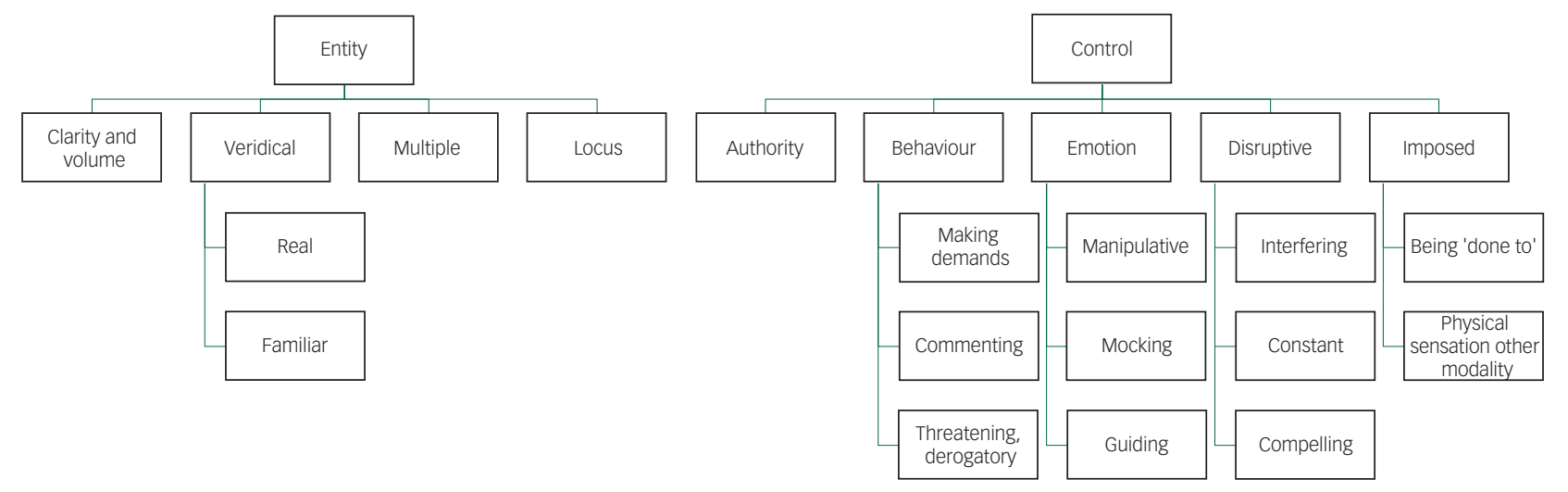




\begin{tabular}{|c|c|c|c|}
\hline Code & $\begin{array}{c}\text { Number } \\
\text { endorsing code }\end{array}$ & Description & Quote \\
\hline Locus & 17 & $\begin{array}{l}\text { Varied experience that changed with time and situation } \\
\text { Location of voices did not appear to affect auditory quality } \\
\text { or 'realness' of the experience } \\
\text { Identifying where voices were coming from could be } \\
\text { confusing }\end{array}$ & $\begin{array}{l}\text { 'When they're shouting it sounds like they're coming } \\
\text { from in my head' } \\
\text { 'I hear it as an exterior voice, it's not as if I have a } \\
\text { thought...' } \\
\text { 'It just seems like they're inside your head, I dunno' }\end{array}$ \\
\hline $\begin{array}{l}\text { Clarity and } \\
\text { volume }\end{array}$ & 9 & $\begin{array}{l}\text { Audible quality of voices described as being both clear } \\
\text { and loud }\end{array}$ & $\begin{array}{l}\text { 'It sounds like, imagine two men just standingbehind } \\
\text { you having a conversation in a pub, that's how loud } \\
\text { they are' } \\
\text { 'When it does come loud all of a sudden you'll } \\
\text { stand up and think... what was that?' } \\
\text { 'When it's loud it's a booming voice... it's like I } \\
\text { struggle not to hear it, it's so loud' }\end{array}$ \\
\hline Multiple & 11 & $\begin{array}{l}\text { Male and female, adults and children, taking it in turns to } \\
\text { speak or talking simultaneously. Multiple voices described } \\
\text { in terms of their personal characteristics }\end{array}$ & $\begin{array}{l}\text { 'Multiple voices, five six voices at the same time... } \\
\text { Right after each other like a runaway train' } \\
\text { 'Some were good, some were greedy, some were } \\
\text { bad' } \\
\text { 'Voices through the TV said Lorraine's a complete } \\
\text { nut job, he goes stay away from her Tommy' }\end{array}$ \\
\hline \multicolumn{4}{|l|}{ Veridicality } \\
\hline Real & 10 & $\begin{array}{l}\text { Realness' voices, difficult to distinguish between reality } \\
\text { Surprise in realising that others could not hear voice }\end{array}$ & $\begin{array}{l}\text { 'It does feel so real, it's just like someone's talking to } \\
\text { me right next to me sometimes' } \\
\text { 'I only found out that the voices weren't real } \\
\text { when I asked people I knew, I said can you hear } \\
\text { these and they said no we can't' }\end{array}$ \\
\hline Familiar & 12 & $\begin{array}{l}\text { Perceived familiarity of voices } \\
\text { Voices were recognised and tended to be heard as though } \\
\text { part of a conversation } \\
\text { Unique and personal manner of voices }\end{array}$ & $\begin{array}{l}\text { 'At first, it was my Uncle's that I could hear... } \\
\text { "You've got to chill out and that lad", man...' } \\
\text { 'They're using voices that you recognise from back } \\
\text { in the day' } \\
\text { 'It's like, say like a mother duck, you've got a } \\
\text { duckling, the duckling knows that call innit, so if it's } \\
\text { family and that, speaking and that' }\end{array}$ \\
\hline
\end{tabular}

Commenting. Several participants reported experiencing a commenting voice, which would often make statements about their daily activities.

Threatening: violent, derogatory and angry. Voices asserted control by physically threatening participants. The content of threats ranged from somewhat ambiguous to specific threats with graphic violent content. Threatening comments would typically be emphasised by an aggressive tone of voice.

\section{Ability to control emotions}

Participants reported that their voices could influence their emotions to the extent that the voice was in control of what was experienced. This was conducted through a variety of complex exchanges and interactions.

Manipulative/tricking. Voices were also described in terms of having emotional control over participants. This includes the manipulative nature of voices, in particular their ability to 'use' the individual's own information to trick participants into following their authority. Participants typically felt as though their voices were trying to mislead them.

Blaming and mocking. Several participants reporting hearing an accusatory voice, which would criticise choices or decisions they had made. Participants often believed that they were being punished by their voices. The general tone of statements made by voices was mocking and, in some instances, proceeded by sarcastic laughter. Participants also described how their voices would ridicule them, calling them names, such as 'stupid' or 'idiot'.

Helpful/guiding. Occasionally voices were found to be helpful, offering participants guidance and support. The advice that was given was broad in content, yet also could be as specific as 'telling me to avoid certain roads or... maybe get out a bit earlier or do certain things for my own good'. Those who experienced a helpful voice often spoke about this as being 'protective', able to assert itself and to defend participants in times of need.

\section{Disruption}

Participants felt that their voices had disrupted and, in numerous cases, completely halted their lives. The majority spoke about how they were unable to concentrate, which, for some, resulted in loss of roles, relationships and employment.

Interfering. Day-to-day life became a constant battle, in which participants would be continually hindered by their voices. Participants described how even the simplest of tasks could suddenly become extremely arduous. Several participants reported that their voices were so interfering, to the extent that their lives had been destroyed.

Constant. A common theme throughout interviews was the constant occurrence of voices, with many participants reporting that this was an ongoing experience. Some described their voices as continually being in the background, whereas other voices were more prominent and harassing. Participants tended to report that voices were typically unrelenting.

Compelling. Participants often found their voices difficult to ignore. Several described feeling urged to follow their voices, not necessarily through their own choice, but because they found them so compelling. In some cases, participants' attention would be diverted solely to their voices, making them the absolute focus of awareness. 
Imposed

Experienced as being 'done to'. Participants frequently described themselves as being completely passive in the experience of their voices and, consequently, helpless in situations where their voices would occur. Described as more than a lack of control over voices, there was a reported perception of passivity in the experience; one participant reporting 'my ears are made to hear it'.

Physical imposition and additional sensations. Participants also reported voice experience as a physically imposed experience. Voices were accompanied by pain, itching or physical force. Overall, there was a real sense that voices forced themselves on participants that in totality resulted in more than an auditory experience.

See the data supplement for illustrations linked to codes.

\section{Discussion}

This extensive qualitative study of AVH in first-episode psychosis from participant's primary descriptions reports on the complex and intricate nature of the quality of experiences. We have grouped these into two overarching themes of entity and control. Our results provide not only confirmation but also additional information of the phenomenology of AVH experienced in psychosis.

Participants reported AVH along dimensions of clarity and volume, that voices had an experience of utter 'realness', were experienced often as many voices and spoke in complex sentences. From first-hand report, hallucinations thus resemble true perceptions and have all the vividness of real experience. They were accompanied by a subjective sense of a lack of control, authority and were disruptive by their interfering, constant and compelling nature. Our results thus confirm previous literature dating back to early psychopathology. Reflecting Jaspers, we have shown a pattern of complex and veridical AVH in early psychosis, from subjective descriptions and before repeated questioning and framing of experience within healthcare settings. Our results suggest complexity is evident from the first episode of psychosis. In 1999, in their seminal paper, Nayani \& David reported complexity increased with severity, and our results would concur with this within a firstepisode psychosis sample. ${ }^{25}$ Many other previous studies using standardised measures report volume, controllability, commenting and number of voices as key aspects. These latter features were also highlighted as those with better ability to distinguish from clinical and non-clinical groups. ${ }^{26}$ Alternatively, voice location was described in our results as a confusing dimension; participants not only reported internal, external and mixed locations but also that this was unclear, difficult to describe and a changeable part of their experience. This suggests that this may indeed be the least clinically useful aspect and one that would not lend itself to robust research.

Novel findings from our study include the extent of $\mathrm{AVH}$ trying to control behaviour and emotions, the experience of $\mathrm{AVH}$ as an entity with complex social interactions and voices being imposed on individuals and occurring with multisensory additional factors.

In terms of AVH as controlling experiences, our results add additional evidence to a perceived lack of control and voice power in clinical populations. ${ }^{27}$ Many studies also focus on the power patients ascribe to $\mathrm{AVH}$, and this is an aspect with clinical relevance, in terms of AVH as a traumatic experience, suicidal ideation, acting on commands and persistence of voices, that our results also support. ${ }^{27,28} \mathrm{~A}$ number of participants reported the voice making demands, which may be likened to commands, but the assumption of instruction with power implied by a commanding voice should not be assumed. Voices were also often perceived as threatening and commenting on actions. These codes, which we have themed control of behaviour, are reflective of that already documented in descriptive psychopathology. ${ }^{2}$ Although voice authority was a feature from our primary data, this was a nuanced and more complex experience whereby voices were trying to gain authority and power through extensive and complex social interactions: manipulating comments, mocking, tricking and blaming. Emotional content is suggested as a discriminating feature of AVH in psychotic disorders by Daalman et al. ${ }^{26}$ Our theme of emotional control concurs with this as a key area of future research and one that may have further clinical relevance in terms of risk of suicidal ideation and acts.

The suggestion of voice entity, over and above a realness of voice hearing, is also a novel finding which closely ties in with work that suggests voices are more than hallucinated sound. Bell proposes a social cognitive model of voice hearing in hallucinated social identities and one that is primarily a social relationship, with social environment predisposing to voice hearing from early childhood and later development. ${ }^{29}$ We have previously shown that within psychosis, childhood trauma may have a symptom-specific risk for hallucinatory experiences; however, the aetiological process whereby people who hear voices acquire what amounts to internalised social actors is under-researched. ${ }^{10,30}$ In terms of neurocognitive models of AVH experience in psychosis, selfmonitoring deficits may explain positive symptoms including hallucinations and passivity phenomena in schizophrenia with sensory confusion of self from non-self. ${ }^{31}$ deWeijer et al and others suggested AVH could be related to an error in 'corollary discharge'. This is the process by which the initiation of a thought or act, such as speech, is accompanied by an alteration in neuronal discharges that alert the individual to the fact that such a thought or act is selfgenerated. ${ }^{32}$ With a self-generated thought or movement, accompanying signals to the sensory and motor cortex inform parts of the brain about an intended action, allowing the sensory areas to predict this possibility and code the sensory consequences as the expected consequence of this action. Allen et $\mathrm{l}^{33}$ suggested that in schizophrenia there is a predictive coding error that accounts for the perceived externality or misattribution of internally generated speech to an external source. Thus, this may explain the realness and auditory quality of voices. The development of complex social interactions with voices are highlighted in our results and this area remains open to investigation.

Our other novel findings of AVH experience include an emphasis on imposition; the sensation of 'being done to' with passivity. Traditionally, 'true hallucinations' occurring in psychotic disorders are conceived of as indistinguishable from real perceptions except that there is no stimulus. Jaspers' view is that normal perceptions and true hallucinations are received with an attitude of passivity. By this he meant that the experience could not be altered by force of will. ${ }^{34}$ Our data further suggest that for patients with psychosis and $\mathrm{AVH}$, this aspect of experience is accentuated. With ordinary speech, there is the option to ignore what someone is saying, to block it out, to change focus to other things or simply leave the room. With $\mathrm{AVH}$ in psychosis one cannot escape the experience and the verbal hallucination has a compelling and controlling dimension that renders it inescapable. Again, the role of corollary discharge may be relevant in the generation of this imposed AVH experience. ${ }^{35}$ Alternatively, within a psychosis sample, positive symptoms that are the result of salience dysregulation would be expected to be accompanied by a subjective experience of 'draw' or compulsion to a given salient stimuli. This would be in keeping with Howes et $\mathrm{al}^{9}$ and their distinction between psychotic and non-psychotic voices driven by dopamine dysregulation.

Finally, our novel findings include AVH experienced with additional multisensory factors, including pain, pressure and itching. Together with the reported feelings of imposition and control, the suggestion is that in this population there is an overlap 


\section{Table 3 Theme 2: control

Number
endorsing
code

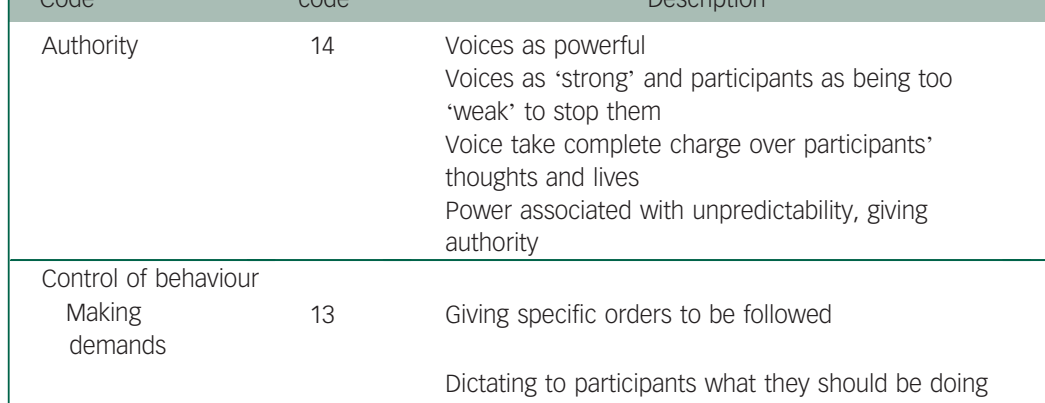

Commands given that prevented opportunity for

Commenting

Threatening

8

Physically threatening participants

Threats often accompanied by swearing

Forceful or angry further thought or discussion

commenting statements about their daily activities

\section{Quote}

'It's the main part of my life at the minute yeah and I am pretty powerless to stop it because of how strong it is'

'If it's really strong, the pull'

'’'m always wary of it at the back of my mind,

that it might happen'

'I got no power, no intention, I can’t block it at all'

'I went to have like a relaxing sit down in the front room and the voices were saying "Get up, get up"

'You take that or you don't take that, eat this or you don't eat this'

'The way it would reply is no kind of open-ended questions, it'll always be in a statement manner'

'Oh she's writing in the diary, oh she's managed to go up the stairs'

'Bitch is going to start a diary'

'We're going to get you'

'If you don't take it what we'll do is we'll burn you in hot water, boiled water'

"“Bitch," they added the swearing... I felt quite threatened by them,

'They're really aggressive or angry, shouting'

$\begin{gathered}\text { Control of } \\ \text { emotions } \\ \text { Manipulative, } \\ \text { tricking }\end{gathered}$
$\begin{aligned} & \text { Manipulative nature of voices } \\ & \text { Ability to 'use' the individual's own voice to trick } \\ & \text { participants } \\ & \text { Voices were trying to mislead or create doubt } \\ & \text { Blaming and } \\ & \text { mocking }\end{aligned}$
$\begin{aligned} & \text { Blaming or accusatory voice, which would criticise } \\ & \text { their choices or decisions, mocking, ridiculing, calling } \\ & \text { names }\end{aligned}$

Helpful/guiding $5 \quad$ Helpful, offering guidance and support Protective, able to defend participants in times of need

'Male voice can use my own voice against me...'

'Creating situations, making me think that'

'Look at what you've done... the impact of you and the decisions you've made'

'I must have been doing something wrong back in the day' "He was like "Ha ha, you deserved it because you brought all this pain and suffering",

"'Ha ha, you deserved it",

'Idiot... be like a man'

'They would tell me that it's not... so bad and tell me to calm down... help'

'Telling me to avoid certain roads or... maybe get out a bit earlier or do certain things for my own good, 'l'll make sure you come out on top'

Disruption
Interfering $17 \quad \begin{aligned} & \text { Participants struggle to function; continually being } \\ & \text { hindered by their voices Interfering, to the extent } \\ & \text { that their lives had been destroyed }\end{aligned}$

Constant $14 \quad$ Constant occurrence of voices

Voices as continually being in the background,

voices were typically unrelenting

Compelling

Voices difficult to ignore

Urged to follow their voices, not necessarily through

their own choice, but because they found them so compelling

Attention diverted solely to their voices, the absolute focus of awareness

'I couldn't be out in pub, I didn't want to out in public or anything, I didn't want to be around crowds cause... I'd hear voices through the people'

'l'm trying to do something normal like have a cup of tea and they're bothering me'

'I ain't got a life anymore really... I can't do anything'

'All day, every day'

'It's constantly niggling you'

'Constantly bombarding you'

'You can't get away from it'

'What you're meant to be doing is looking at me

and answering me, however, you need to be

paying attention to what they're saying'

'Anything that's going on around me just seems to fade

away and I'm just concentrating on what the

voices are telling me'

'It eggs me on'

Imposed

Experienced as

17

being 'done to'

Participants passive in the experience

Voices force themselves upon participants who were unable to stop hearing them
'It's like being possessed, you know. What can you do?

What can you really do'

'It's like I'm being held down'

'I'm constantly caged in by voices'

'My body will recognise it'

'When they choose to talk to me, they choose to talk to

me and they take over they take over the whole situation

as it is at the time'

'It's out of my hands'

'if it's really strong, the pull, I just loose whole control of it' 


\begin{tabular}{|c|c|c|c|}
\hline Code & $\begin{array}{l}\text { Number } \\
\text { endorsing } \\
\text { code }\end{array}$ & Description & Quote \\
\hline $\begin{array}{l}\text { Physical } \\
\text { imposition and } \\
\text { additional } \\
\text { sensations }\end{array}$ & 11 & $\begin{array}{l}\text { Reported with bodily sensations } \\
\text { From feeling itchy to actual physical pain, } \\
\text { participants described how strongly their voices } \\
\text { were experienced alongside sensations in other } \\
\text { modalities }\end{array}$ & $\begin{array}{l}\text { 'Giving me pain, giving me physical pain basically... I felt } \\
\text { from inside organ... pain going on' } \\
\text { 'Makes me feel sick' } \\
\text { 'My whole body, its feeling has been changed' } \\
\text { 'It's not even just a voice um it's... I've had like a push on } \\
\text { my shoulder um... I've smelt like things which like you } \\
\text { wouldn't expect...' } \\
\text { 'They poke and prod me and put pressure on me' } \\
\text { 'I can feel it yeah. It's like... acupuncture } \\
\text { pressure on my neck and the back of my head and that' } \\
\text { 'When it happens, I itch for ages' }\end{array}$ \\
\hline
\end{tabular}

between AVH and other positive symptoms of psychosis, such as hallucinations in other modalities or passivity phenomena. This may suggest distinguishing features that could be elicited in the phenomenology of voice-hearing in psychosis. However, recently Woods et al also report phenomenological data from a mixed sample using an online methodology, which included one open question subject to qualitative analysis; voices were also being experienced in a physical dimension, with $18 \%$ of their sample reporting AVH occurring with bodily sensations, including being in a dream-like state, feelings of heat or accompanied by tingling sensations. ${ }^{6}$ Thus, this area needs further research and replication.

McCarthy-Jones et $a l^{36}$ call for subtyping to be a key advance needed in AVH research. Cutting across diagnostic groups, antecedent and treatment responses, and neurological categories, they propose that phenomenological subtypes include 'hypervigilance', 'inner speech', 'autobiographical memory', 'epileptic' and 'deafferentation'. Our direct patient reports offer confirmation that some aspects of AVH in psychosis may be captured by these proposed groupings; however, additional factors would need further expansion. Primary research from our qualitative data reinforces the proposal that integration of methods in investigating AVH need stronger qualitative phenomenological focus. ${ }^{37}$ One limitation highlighted in the past literature includes the repeated use of standardised measures to record voice-hearing phenomenology. ${ }^{10}$ These include the Brief Psychiatric Rating Scale and the Positive and Negative Syndrome Scale, which measure frequency and disruption, ${ }^{38,39}$ and the Psychotic Symptom Rating Scale, which rates location, loudness, distress, controllability and beliefs. ${ }^{40}$ In terms of content and power, the Beliefs About Voices Questionnaire rates benevolence, malevolence, omnipotence, resistance and engagement and the Voice Power Differential Scale rates voice power. ${ }^{41,42}$ However, even in their totality, the novel phenomenological features we report, including the extent of social relationship and emotional control, imposition and multisensory additional features would not be captured.

This study has a number of strengths. Our use of novel, qualitative techniques allowed a more reflexive and direct aspect to AVH experience, and a mobile interview allowed participants to describe their experience in a non-threatening, open setting. By using diaries and photos collected prior to interview, the information we have gleaned was less 'tainted' by the researcher's questioning and should, therefore, be a credible representation of the nature of such experiences. Methodologies used were in-depth and aimed at gaining true first-hand accounts in a sample that is large in terms of qualitative research. Photo elicitation is a technique that is particularly useful in mental health research as it affords individuals the opportunity to explore feelings and experiences that may otherwise be difficult to articulate. ${ }^{43}$ Without the use of $a$ priori dimensions, standard questionnaires or structured interviews, we have been able to capture AVH aspects that participants themselves feel are most important. We were also able to continue interviewing until data saturation (i.e. no new themes emerged), giving confidence that the essence of the experience was captured within our sample.

The study does however have clear limitations. The sample of patients with psychosis, although our intended focus, could reflect a group identified with diagnostic criteria that already include frequent and complex voices, and as such our results only reflect this limited nosology. However, it is clear from literature that the diagnostic outcome from first-episode psychosis is broad, including affective and non-affective psychoses. ${ }^{44}$ Replication of our extensive qualitative methodology in non-psychotic groups is needed before any firm conclusions can be drawn. Although our sample contained participants from both genders, participants were predominantly male and from a White ethnic group. Future research is also needed using this methodology in non-help-seeking populations, and other cultures, to ascertain whether AVH experience is similar in these differing populations.

However, our results should be of clear interest to clinical, translational and biological researchers. Studies aiming to understand the underlying neuropathology of auditory hallucinations have been challenging. Neuroimaging studies looking to distinguish psychotic from non-psychotic AVH produced mixed results, ${ }^{37,45}$ and it may be that some aspects of AVH are common across all voice-hearing populations; however, key distinctions in psychotic voices, if present, have not been captured by studies using standardised rating scales. Our results should provide a starting point for future research aiming to address these questions and suggest that the themes of voice entity and control with their associated codes (see Tables 2 and 3) are important aspects to study and ones that may suggest areas of key clinical relevance.

Rachel Upthegrove, MBBS, MRCPsych, PhD, School of Clinical \& Experimental Medicine, University of Birmingham, Birmingham, UK; Birmingham and Solihull Mental Health Foundation Trust, Birmingham, UK; Jonathan Ives, PhD, Medicine, Ethics, Society and History, University of Birmingham, Birmingham, UK; Matthew R. Broome MBChB, MRCPsych, PhD, Department of Psychiatry, University of Oxford, Oxford, UK; Warneford Hospital, Oxford Health NHS Foundation Trust, Oxford, UK; Division of Mental Health and Wellbeing, Warwick Medical School, University of Warwick, Coventry, UK; Kimberly Caldwell, MSC, School of Clinical \& Experimental Medicine, University of Birmingham, Birmingham, UK; Birmingham and Solihull Mental Health Foundation Trust, Birmingham, UK; Stephen J. Wood, MA (Cantab), PhD, School of Psychology, University of Birmingham, Birmingham, UK; Melbourne Neuropsychiatry Centre, Department of Psychiatry, University of Melbourne \& Melbourne Health, Carlton, Victoria, Australia; Femi Oyebode, MBBS, MD, PhD, FRCPsych, School of Clinical \& Experimental Medicine, University of Birmingham, Birmingham, UK; Birmingham and Solihull Mental Health Foundation Trust, Birmingham, UK

Correspondence: Rachel Upthegrove, MBBS MRCPsych PhD, Clinical Senior Lecturer School of Clinical and Experimental Medicine, University of Birmingham, 25 Vincent Drive, Birmingham B15 2F, UK. Email: r.upthegrove@bham.ac.uk

First received 15 Oct 2015, final revision 4 Jan 2016, accepted 5 Jan 2016 


\section{Funding}

This study was funded by Healthy Minds Charitable Trust and Birmingham \& Solihull Mental Health Foundation Trust.

\section{References}

1 Waters F, Allen P, Aleman A, Fernyhough C, Woodward TS, Badcock JC, et al Auditory hallucinations in schizophrenia and nonschizophrenia populations: review and integrated model of cognitive mechanisms. Schizophr Bull 2012; 38 683-93.

2 Oyebode F. Sims' Symptoms in the Mind: Textbook of Descriptive Psychopathology. Elsevier Health Sciences, 2014

3 Anthony D. The cognitive neuropsychiatry of auditory verbal hallucinations: an overview. Cogn Neuropsychiatry 2004; 9: 107-23.

4 Bak M, Myin-Germeys I, Hanssen M, Bijl R, Vollebergh W, Delespaul P, et al. When does experience of psychosis result in a need for care? A prospective general population study. Schizophr Bull 2003; 29: 349-58.

5 Larøi F, Sommer IE, Blom JD, Fernyhough C, Ffytche DH, Hugdahl K, et al. The characteristic features of auditory verbal hallucinations in clinical and nonclinical groups: state-of-the-art overview and future directions. Schizophr Bull 2012; 38 : 724-33.

6 Woods A, Jones N, Alderson-Day B, Callard F, Fernyhough C. Experiences of hearing voices: analysis of a novel phenomenological survey. Lancet Psychiatry 2015; 2: 323-31.

7 Slotema C, Daalman K, Blom J, Diederen K, Hoek H, Sommer I. Auditory verbal hallucinations in patients with borderline personality disorder are similar to those in schizophrenia. Psychol Med 2012; 42: 1873-8.

8 Looijestijn J, Diederen KM, Goekoop R, Sommer IE, Daalman K, Kahn RS, et al. The auditory dorsal stream plays a crucial role in projecting hallucinated voices into external space. Schizophr Res 2013; 146: 314-9.

9 Howes OD, Shotbolt P, Bloomfield M, Daalman K, Demjaha A, Diederen KMJ, et al. Dopaminergic function in the psychosis spectrum: an [18F]-DOPA imaging study in healthy individuals with auditory hallucinations. Schizophr Bull 2013; 39: 807-14.

10 Stanghellini G, Langer Ál, Ambrosini A, Cangas AJ. Quality of hallucinatory experiences: differences between a clinical and a non-clinical sample. World Psychiatry 2012; 11: 110-3.

11 O'Connor $K_{\text {, Nelson }}$, Lin A, Wood SJ, Yung A, Thompson A. Are UHR patients who present with hallucinations alone at lower risk of transition to psychosis? Psychiatry Res 2016; 235: 117-96.

12 Broome MR, Harland R, Owen GS, Stringaris A. The Maudsley Reader in Phenomenological Psychiatry. Cambridge University Press, 2013

13 Stanghellini G, Broome MR. Psychopathology as the basic science of psychiatry. Br J Psychiatry 2014; 205: 169-70.

14 Lataster T, Valmaggia L, Lardinois M, van Os J, Myin-Germeys I. Increased stress reactivity: a mechanism specifically associated with the positive symptoms of psychotic disorder. Psychol Med 2013; 43: 1389-400.

15 Woods A, Jones N, Bernini M, Callard F, Alderson-Day B, Badcock JC, et al. Interdisciplinary approaches to the phenomenology of auditory verbal hallucinations. Schizophr Bull. 2014; 40 (suppl 4): S246-54.

16 Goldsmith LP. A discursive approach to narrative accounts of hearing voices and recovery. Psychosis Psychol Soc Integr Approaches 2012; 4: 235-45.

17 Sandhu A, Ives J, Birchwood M, Upthegrove R. The subjective experience and phenomenology of depression following first episode psychosis: a qualitative study using photo-elicitation. J Affect Disord 2013; 149: 166-74.

18 Upthegrove R, Birchwood M, Ross K, Brunett $K$, McCollum R, Jones L. The evolution of depression and suicidality in first episode psychosis. Acta Psychiatr Scand 2010; 122: 211-8.

19 World Health Organization. International Classification of Diseases (ICD-10) WHO, 1991.

20 Erdner A, Magnusson A. Photography as a method of data collection: helping people with long-term mental illness to convey their life world. Perspect Psychiatr Care 2011; 47: 145-50.

21 Harper D. Talking about pictures: a case for photo elicitation. Visual Stud 2002; 17 $13-26$.

22 Harrington C, Lindy I. The Use of Reflexive Photography in the Study of the Freshman Year Experience. Taylor and Francis, 1998.

23 Krippendorff K. Content Analysis: An Introduction to its Methodology. Sage, 2012

24 Hsieh H-F, Shannon SE. Three approaches to qualitative content analysis. Qual Health Res 2005; 15: 1277-88.

25 Nayani TH, David AS. The auditory hallucination: a phenomenological survey. Psychol Med 1996; 26: 177-89.

26 Daalman K, Boks M, Diederen K, de Weijer AD, Blom JD, Kahn RS, et al. The same or different? A phenomenological comparison of auditory verbal hallucinations in healthy and psychotic individuals. J Clin Psychiatry 2011; 72: 320-5.

27 Upthegrove R, Ross K, Brunet K, McCollum R, Jones L. Depression in first episode psychosis: the role of subordination and shame. Psychiatry Res 2014; 217 $177-84$

28 Birchwood M, Iqbal Z, Upthegrove R. Psychological pathways to depression in schizophrenia: studies in acute psychosis, post psychotic depression and auditory hallucinations. Eur Aarch Psychiatry Clin Neurosci 2005; 255: 202-12.

29 Bell V. A community of one: social cognition and auditory verbal hallucinations. PLOS Biol 2013; 11: e1001723.

30 Upthegrove R, Chard C, Jones L, Gordon-Smith K, Forty L, Jones I, et al. Adverse childhood events and psychosis in bipolar affective disorder. Br J Psychiatry 2015; 206: 191-7.

31 McGuire P, David A, Murray R, Frackowiak R, Frith C, Wright I, et al. Abnormal monitoring of inner speech: a physiological basis for auditory hallucinations. Lancet 1995; 346: 596-600.

32 de weijer $A D$, Neggers SF, Diederen $K$, Mandl RC, Kahn RS, $\mathrm{Pol} H$, et al. Aberrations in the arcuate fasciculus are associated with auditory verbal hallucinations in psychotic and in non-psychotic individuals. Hum Brain Mapp 2013; 34: 626-34.

33 Allen P, Modinos G, Hubl D, Shields G, Cachia A, Jardri R, et al. Neuroimaging auditory hallucinations in schizophrenia: from neuroanatomy to neurochemistry and beyond. Schizophr Bull 2012; 38: 695-703.

34 Jaspers K. General Psychopathology. JHU Press, 1997.

35 Heinks-Maldonado TH, Mathalon DH, Houde JF, Gray M, Faustman WO, Ford JM Relationship of imprecise corollary discharge in schizophrenia to auditory hallucinations. Arch Gen Psychiatry 2007; 64: 286-96.

36 McCarthy-Jones S, Thomas N, Strauss C, Dodgson G, Jones N, Woods A, et al. Better than mermaids and stray dogs? Subtyping auditory verbal hallucinations and its implications for research and practice. Schizophr Bull 2014; 40 (suppl 4): S275-84.

37 Upthegrove R, BM, Caldwell K, Ives J, Oyebode F, Wood SJ. How we Understand Hallucinations; a systematic review of current evidence. Acta Psychiatr Scand 2015; 15 Dec, doi: 10.111/acps.12531.

38 Hedlund JL, Vieweg BW. The Brief Psychiatric Rating Scale (BPRS): a comprehensive review. J Oper Psychiatry 1980; 11: 48-65.

39 Kay SR, Flszbein A, Opfer LA. The positive and negative syndrome scale (PANSS) for schizophrenia. Schizophr Bull 1987; 13: 261.

40 Haddock G, McCarron J, Tarrier N, Faragher E. Scales to measure dimensions of hallucinations and delusions: the psychotic symptom rating scales (PSYRATS) Psychol Med 1999; 29: 879-89.

41 Chadwick P, Lees S, Birchwood M. The revised Beliefs About Voices Questionnaire (BAVQ-R). Br J Psychiatry 2000; 177: 229-32.

42 Birchwood M, Meaden A, Trower P, Gilbert P, Plaistow J. The power and omnipotence of voices: Subordination and entrapment by voices and significant others. Psychol Med 2000; 30: 337-44.

43 Kantrowitz-Gordon I, Vandermause R. Metaphors of distress photo-elicitation enhances a discourse analysis of parents' accounts. Qual Health Res 2015; pii: 1049732315575729. (Epub ahead of print)

44 Heslin M, Lomas B, Lappin J, Donoghue K, Reininghaus U, Onyejiaka A, et al. Diagnostic change 10 years after a first episode of psychosis. Psychol Med 2015; 45: 2757-69.

45 Diederen KM, Daalman K, de Weijer AD, Neggers SF, van Gastel W, Blom JD, et at. Auditory hallucinations elicit similar brain activation in psychotic and nonpsychotic individuals. Schizophr Bull 2012; 38: 1074-82. 